\title{
Signal transduction mechanisms in nutrient-induced insulin secretion
}

\author{
M. Prentki ${ }^{1}$, K. Tornheim ${ }^{2}$, B.E . C orkey ${ }^{2}$ \\ ${ }^{1}$ Molecular Nutrition Unit, Department of Nutrition and Centre de Recherche L.-C. Simard, Institut du Cancer de Montreal, \\ University of Montreal, Montreal, Canada \\ ${ }^{2}$ Diabetes and Metabolism Unit, Evans Department of Medicine and Department of Biochemistry, \\ Boston University Medical Center, Boston, Massachusetts, USA
}

Summary The knowledge of the mechanism whereby glucose and other fuel stimuli promote the release of insulin by the pancreatic beta cell remains fragmentary. The closure of metabolically sensitive $\mathrm{K}^{+}$channels and a rise in cytosolic free $\mathrm{Ca}^{2+}$ are key features of beta-cell metabolic signal transduction. However, these two signalling events do not account for the dose dependence of glucose-induced insulin secretion. In fact, recent evidence indicates that there are $\mathrm{K}_{\text {ATP }}$ channel and $\mathrm{Ca}^{2+}$ independent pathway(s) of beta-cell activation which remain to be defined. In this review, we have limited our attention to the recent developments in our understanding of the mode of action of nutrient secretagogues. A particular emphasis is placed in summarising the evidence in support of two new concepts: 1) oscillations in the glyco- lytic pathway and beta-cell metabolism contribute to the oscillatory nature of beta-cell ionic events and insulin secretion; 2) malonyl-CoA and long chain acylCoA esters may act as metabolic coupling factors in beta-cell signalling. Finally, we propose that the altered expression of genes encoding enzymes in the pathway of malonyl-CoA formation and fatty acid oxidation contributes to the beta-cell insensitivity to glucose in some patients with non-insulin-dependent diabetes mellitus. [Diabetologia (1997) 40: S32-S 41]

Keywords Insulin secretion, malonyl-CoA, long chain acyl-CoA, fatty acid, acetyl-CoA carboxylase, carnitine palmitoyl-transferase I, glycolytic oscillations, anaplerosis, gene expression, non-insulin-dependent diabetes mellitus.
The secretion of insulin by the pancreatic beta cell is modulated by various nutrients, neurotransmitters and peptide hormones [1]. Glucose is the only nutrient secretagogue capable of promoting alone in vitro the release of insulin at concentrations within its physiological range. Nonetheless, many additional nutrients including fatty acids, amino acids and keto acids influence secretion as well. Thus, the islet of

Corresponding author: Dr. B. E. Corkey, Diabetes and Metabolism Unit, Evans Department of Medicine and Department of Biochemistry, Boston University Medical Center, 88 E. Newton Street, Boston, MA 02118, USA

A bbreviations: ACC, Acetyl-CoA carboxylase; CPT I, carnitine palmitoyl-transferase I; NEFA, non-esterified fatty acid; LC-CoA, long chain acyl-CoA ester; L-PK, liver-type pyruvate kinase; PC, pyruvate carboxylase; PFK-1, 6-phosphofructo-1-kinase; PFK-2, 6-phosphofructo-2-kinase; NIDDM, non-insulin-dependent diabetes mellitus.
Langerhans can be viewed as a 'fuel sensor' which simultaneously integrates the signals of many nutrients and modulators to secrete insulin according to the needs of the organism. The unique feature of the beta cell is that it possesses a transduction system for calorigenic nutrient signals which is entirely different from that of neuromodulators or peptide hormones. Indeed, fuel stimuli must be metabolised in the beta cell to cause secretion [2-5]. By contrast, neuromodulators, such as the potent incretin GLP-I [6], influence the secretory process following their interaction with specific cell-surface receptors.

Despite considerable effort, the exact biochemical nature of the signals which couple glucose metabolism to insulin secretion have remained poorly defined. The difficulty of 'cracking the code' of nutrient signalling may stem from the fact that it is perhaps one of the most complex transduction systems which exists because metabolism, whose regulation is so 


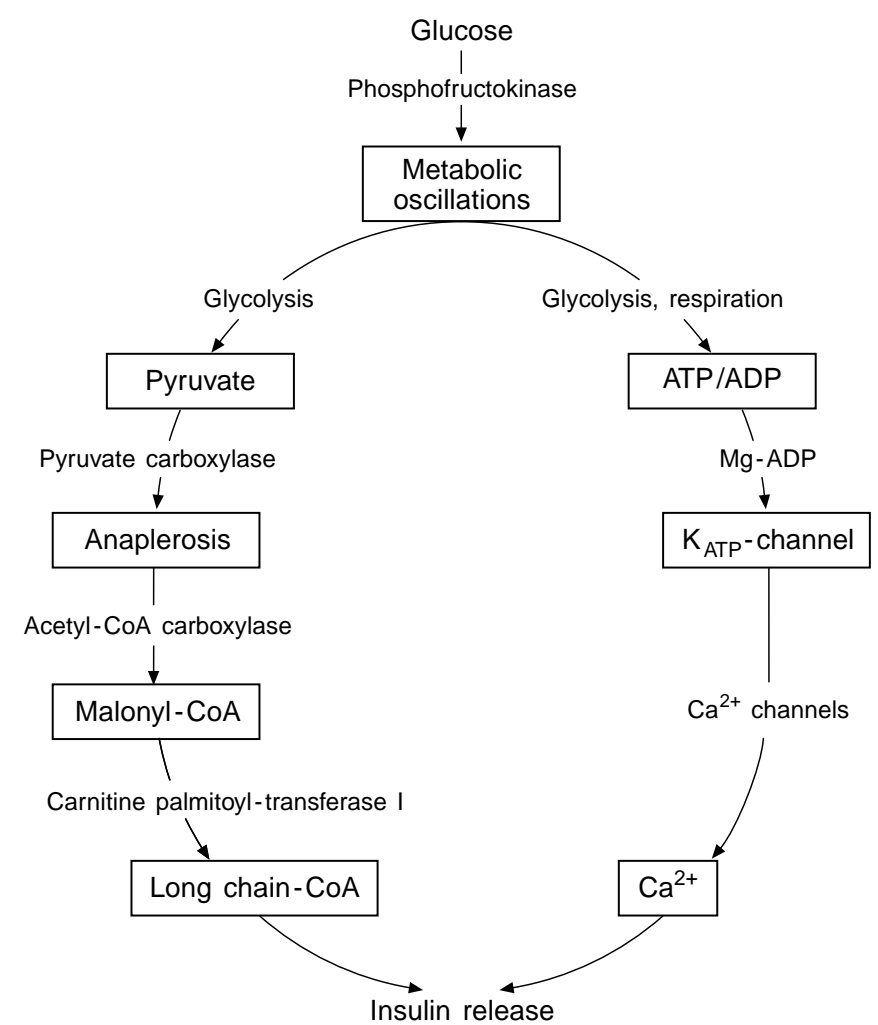

Fig. 1. Model illustrating the role of glycolytic oscillations and the two arms in beta-cell signalling. Oscillations in the metabolism of glucose generate oscillatory $\mathrm{O}_{2}$ consumption, cytosolic ATP/ADP ratio, $\mathrm{K}^{+}$ATP channel opening probability, membrane potential fluctuations and free $\mathrm{Ca}^{2+}$ in the cytoplasm. On the other hand, glucose-derived pyruvate is carboxylated to oxaloacetate by pyruvate carboxylase. This anaplerotic reaction favours the formation of malonyl-CoA by acetyl-CoA carboxylase. Malonyl-CoA in turn inhibits carnitine palmitoyl-transferase I with a resulting elevation of long chain acylCoA esters in the cytoplasm. Elevated free $\mathrm{Ca}^{2+}$ and fatty acyl-CoA synergize to cause full induction of insulin release

complex, is intimately implicated in the process. In addition, the heterogeneity of islet tissue and the scarcity of the material amenable for biochemical studies has added considerable difficulty.

Until recently, it was thought that oxidative events and accelerated ATP generation are the central events causally implicated in insulin secretion. The widely accepted view summarised in the right part of Figure 1 is that metabolically sensitive $\mathrm{K}^{+}$-channels close in response to physiological variations of ATP and/or ADP with resulting opening of voltage-gated $\mathrm{Ca}^{2+}$ channels. As a consequence of $\mathrm{Ca}^{2+}$ influx, cytosolic $\mathrm{Ca}^{2+}$ rises which triggers the exocytotic release of insulin [7]. However, the recent evidence indicates that the picture may be more complex and that what may be named the ' $\mathrm{K}_{\mathrm{ATP}} / \mathrm{Ca}^{2+}$ pathway' does not fully account for the action of nutrient stimuli. Indeed, $\mathrm{K}^{+}$induced insulin secretion, which elevates $\mathrm{Ca}^{2+}$ maximally, causes transient secretion of insulin whereas glucose-induced secretion is sustained [1].
Furthermore, several recent reports showed that glucose stimulates a normal amount of insulin release under conditions where $\mathrm{K}_{\mathrm{ATP}}$ channel closure is bypassed (use of diazoxide) provided that $\mathrm{Ca}^{2+}$ is elevated (use of high $\mathrm{K}^{+}$) $[8,9]$. These observations underscore the existence of $\mathrm{K}_{\mathrm{ATP}}$ channel and $\mathrm{Ca}^{2+}$-independent pathways in the insulinotropic action of glucose [8].

\section{R ole of metabolic oscillations in beta-cell signalling}

O scillations in insulin secretion and intracellular free $\mathrm{Ca}^{2+}$. Insulin secretion in vivo in man and animals and from the perfused pancreas is pulsatile $[10,11]$. This pulsatility is lost in patients with non-insulin-dependent diabetes mellitus (NIDDM) and in their near relatives [12]. This suggests that abnormal oscillatory insulin secretion may be an early phenomenon in the development of NIDDM [12]. We [13, 14] and others $[15,16]$ have demonstrated oscillations in insulin secretion from groups of perifused islets. In addition, transplanted pancreata exhibit oscillations in insulin secretion before the establishment of neural connections [17]. These studies indicate that the oscillatory behaviour is not dependent on a neural network, but rather is an inherent property of the islet. It is therefore attractive to believe that the oscillatory nature of the beta cell is characteristic of the stimulus secretion coupling process, and that at least in the case of glucose-stimulated insulin secretion, it derives from the oscillatory metabolism of glucose $[13,18]$, not increased glycolytic flux per se (Fig. 1).

Spontaneous glycolytic oscillations have been observed widely (see below); they involve oscillations in ADP and the ATP/ADP ratio, which in the pancreatic beta cell could cause opening and closing of $\mathrm{K}_{\mathrm{ATP}}$ channels, leading to oscillations in membrane potential, in the influx of $\mathrm{Ca}^{2+}$ through voltage-gated channels and insulin release. In agreement with this hypothesis oscillations in intracellular free $\mathrm{Ca}^{2+}$ have been observed in single rat [13] and mouse islets [19, $20]$ and in single pancreatic beta cells [21,22]. In addition, cytosolic free $\mathrm{Ca}^{2+}$ and insulin secretion oscillations are tightly correlated as demonstrated in single islets $[19,23]$.

Glycolytic oscillations. Oscillations in the glycolytic pathway have been studied in various cell types including skeletal muscle [24, 25], yeast cells [26, 27], heart [28] and ascites tumour cells [29]. The mechanism of the oscillations in skeletal muscle extracts involves a very unusual form of enzyme regulation in which the product of the phosphofructokinase reaction (PFK-1) activates the enzyme [30, 31]. Indeed, this key glycolytic enzyme is activated by fructose-1, 6-bisphosphate (F16BP) in the micromolar range in an AMP-dependent manner [31]. An extract of 
beta-cell cytosol exhibiting glycolytic oscillations has not been isolated yet due to the difficulty in obtaining enough biological material. As an alternative approach we have used permeabilized insulinoma cells supplemented with a glycolysing cell free muscle extract. Using this system linked oscillations of free $\mathrm{Ca}^{2+}$ and the ATP/ADP ratio were observed [32]. Interestingly, when glucokinase replaced hexokinase as the glucose phosphorylating enzyme, $\mathrm{Ca}^{2+}$ oscillations were induced with increasing glucose from 2 to $8 \mathrm{mmol} / \mathrm{l}$ [32].

Oscillations in NADH fluorescence have been associated with every oscillating glycolytic system so far studied and have in fact been used for monitoring the yeast and heart extract systems. Oscillations in $\mathrm{NAD}(\mathrm{P}) \mathrm{H}$ fluorescence occur in single beta cells on stimulation with glucose [21, 22]. Importantly, the initial rise in $\mathrm{NAD}(\mathrm{P}) \mathrm{H}$ precedes that of $\mathrm{Ca}^{2+}$, consistent with $\mathrm{Ca}^{2+}$ changes being secondary to oscillations in metabolism [22]. Also consistent with the idea that glycolytic oscillations occur in the beta cell are reports indicating that oscillations in $\mathrm{O}_{2}$ consumption [13] and lactate production [18] occur in glucosestimulated islets with the same periodicity as for $\mathrm{Ca}^{2+}$ and insulin release. Rapid NAD(P)H and $\mathrm{Ca}^{2+}$ oscillations of similar frequency have been identified in a sub population of islet cells in culture [22]. The authors hypothesised that subpopulations of beta cells might electrically pace oscillatory $\mathrm{Ca}^{2+}$ influx in islet micro domains. This may explain why NAD $(\mathrm{P}) \mathrm{H}$ oscillations are not observed in single islets [33] in contrast to the electrically coupled $\mathrm{Ca}^{2+}$ transients. Finally, we have observed oscillations in the ATP/ADP ratio and glucose 6-phosphate in a suspension of beta cells synchronised by clonidine treatment [34]. Thus, there is much experimental support for the idea that oscillations in glycolysis and the ATP/ADP ratio contribute at least in part to the oscillations in $\mathrm{Ca}^{2+}$, beta cell electrical activity and insulin release.

Advantages of oscillations. Berridge and Rapp [35] have emphasised the advantages of oscillatory behaviour in signalling, especially the higher signal-to-noise ratio. Simply stated, a relatively infrequent but high pulse is more easily discernible above background than is a constant but small elevation. Frequency-dependent rather than amplitude-dependent signals have been proposed to operate in $\mathrm{Ca}^{2+}$ signalling in other biological systems [35, 36]. In the case of signalling via intracellular free $\mathrm{Ca}^{2+}$, there may also be a practical limitation that favours transient elevations, since a prolonged $\mathrm{Ca}^{2+}$ rise might overload the capacity of $\mathrm{Ca}^{2+}$ storage organelles. Furthermore, sustained elevations in cytosolic $\mathrm{Ca}^{2+}$ may be detrimental to mitochondrial metabolism and ATP generation.

There are additional advantages of regulation by metabolic oscillations in the beta cell. There is economy of energy expenditure since excess ATP is produced only transiently when required to participate in triggering the secretory event. A greater sensitivity to variations in external glucose is another possibility since oscillations in the generation of coupling molecules and hormone secretion are rapidly turned on or off upon variations in the concentration of the sugar. Oscillatory behaviour may also have certain advantages specifically related to hormone action. It has been suggested that oscillations in hormone levels may reduce down-regulation of receptors, and thereby enhance hormone action. There is evidence that pulsatile administration of some hormones, including insulin, enhances their efficiency [11].

It must be underlined that regulation by the amplitude of the signal, in particular the absolute peak and trough values reached, not just the oscillatory behaviour may also be of importance. In this respect it is attractive to hypothesize that the peaks of the ATP/ ADP ratio reached during metabolic oscillations provide the linkage to the $\mathrm{Ca}^{2+}$ oscillations in the islet by virtue of their effect on the $\mathrm{K}_{\mathrm{ATP}}$ channels.

Phosphofructokinase. 6-phosphofructo-1-kinase (PFK1 ) is a key enzyme implicated in the generation of glycolytic oscillations. There are three mammalian isoforms of PFK-1 with differing tissue distribution [37-39]. Adult muscle has only the M-type subunit, and liver mainly the L-type subunit. Brain has Ctype as well as M and L-type subunits [38]. They are transcribed from separate genes and have slightly different apparent molecular weights by SDS-PAGE [40]. PFK-1 isozymes have the same set of activators and inhibitors; however, there are some large differences in affinity for certain regulators. In particular, skeletal muscle PFK-1 is strongly activated by micromolar levels of F16BP [41, 42], whereas there is little if any activation of liver PFK-1 by F16BP in the presence of near physiological concentrations of ATP, AMP and F6P [43]. Thus, the autocatalytic activation of PFK-1 by micromolar levels of F16BP, which is the basis of the glycolytic oscillations in the muscle extract system, would not be expected to occur with the $\mathrm{L}$ and $\mathrm{C}$ isozymes. The situation is actually even more complicated where multiple isozymes are expressed in a given tissue. Indeed, PFK-1 is a tetramer and the subunits most likely associate in all combinations, not just the $\mathrm{M}_{4}, \mathrm{~L}_{4}$ and $\mathrm{C}_{4}$ complexes. The kinetics of the hybrids are probably intermediate between those of the homotetramers, but have not been investigated.

The few studies of PFK-1 activity in islet extracts have shown inhibition by ATP and citrate and activation by AMP and fructose-2,6-bisphosphate (F26BP) [44-46]. This is a characteristic feature of all the isozymes to various degrees. Recent PFK-1 protein analyses and kinetic studies with pancreatic islets and clonal beta cells (INS-1) have revealed the presence of both the $\mathrm{M}$ and $\mathrm{C}$ isoforms, with a smaller 
amount of the L isozyme [47]. Kinetic studies of PFK1 activity in INS-1 cell extracts showed strong activation by micromolar levels of F16BP at near physiological concentrations of ATP, AMP and fructose 6phosphate, indicative of the M-type isoform. Activation by submicromolar concentrations of F26BP and potent inhibition by citrate were also observed. The F16BP stimulated activity was about half that caused by F26BP [47]. These experiments demonstrate the presence in beta cells of the M-type isoform of PFK1 which has the requisite regulatory properties for generating glycolytic oscillations.

There are also tissue-specific isozymes of 6-phosphofructo-2-kinase (PFK-2), the enzyme which synthesises F26BP, a strong activator of PFK-1 and glycolysis [30, 43]. Glucose stimulation has been reported to increase F26BP substantially in normal islets [45], but this was called into question by other authors [48]. Hence, the role of PFK-2 in beta cell glycolysis remains to be defined.

\section{M itochondrial metabolism and the generation of coupling factors}

O xidative events and anaplerosis. Various mitochondrial uncouplers and respiration inhibitors impair the secretion of insulin promoted by glucose and by nutrients that are directly metabolised in the mitochondrion [2], This has lent support to the 'fuel hypothesis' proposing that mitochondrial oxidative events and ATP generation are key factors in beta cell activation [2]. Although this view is attractive, recent evidence suggests that accelerated production of acetyl-CoA, which is required for enhanced $\mathrm{O}_{2}$ consumption and ATP generation, does not solely account for full induction of insulin secretion. As indicated above, there is ample pharmacological evidence demonstrating the existence of $\mathrm{K}_{\mathrm{ATP}}$ channel independent secretion. Furthermore, substrates which are directly metabolised to acetyl-CoA, i.e. fatty acids and ketone bodies, require the presence of glucose to elicit secretion [1]. Finally, leucine, which is metabolised to acetyl-CoA, synergizes with glutamine which directly enters the citric acid cycle via alpha-ketoglutarate [49]. These considerations led us to propose that anaplerosis, which allows the direct replenishment of the Krebs' cycle with intermediates, is also a key event in beta cell signalling (Fig. 1) [50, 51]. Consistent with this view, the islet tissue contains large amounts of pyruvate carboxylase (PC) which catalyses the formation of the intermediate oxaloacetate. Thus, $0.4 \%$ of islet protein is PC [52]. It is generally believed that PC is abundant only in gluconeogenic and lipogenic tissues. However, the islets of Langerhans do not synthesise glucose de novo [53] and have a very low lipogenic capacity [54]. It is attractive to hypothesize that a reason for the abundance of PC is that accelerated flux through the enzyme will permit a rise in citrate, the carbon precursor of the putative coupling factor malonyl-CoA. Consistent with this idea, glucose causes a rapid elevation of both citrate [55] and malonyl-CoA in clonal $\beta$ cells $[50,56]$. Another possibility is that the abundance of $\mathrm{PC}$ allows the existence of a pyruvate/malate shuttle for cytosolic NADPH production [52].

A denine nucleotides and reducing equivalents. Nutrients which are initially metabolised via diverse pathways before entering the Krebs' cycle elicit similar changes in various parameters of beta cell activation [57]. It is therefore attractive to believe that the beta cell coupling factors are high energy molecules which are common to the metabolism of all fuel stimuli, rather than particular metabolites specific to a given pathway, such as a glycolytic intermediate. The identification of these factors remains a formidable task and is central to the understanding of how glucose causes the release of insulin. As illustrated in Figure 2 the currency molecules or energy parameters which are common to all fuel stimuli include adenine nucleotides, the redox state and acyl-CoA compounds.

Adenine nucleotides are prime candidate coupling factors because they modulate the activity of the $\mathrm{K}_{\text {ATP }}$ channel. However, it remains uncertain whether they are the true physiological regulators of the $\mathrm{K}_{\text {ATP }}$ channel because the activity of this channel is also altered by numerous compounds including various non-esterified fatty acids (NEFA), phospholipids, fatty acyl-CoA esters, and pyridine nucleotides [58, 59] whose cellular contents are expected to vary following beta cell activation by fuels. Furthermore, recent studies have shown that above $5 \mathrm{mmol} / \mathrm{l}$ glucose does not cause [60] or causes a very modest [61] elevation in islet ATP. It is possible that local cytoplasmic elevations in ATP play a role or that important variations in cytosolic ATP and the ATP/ADP ratio are not detected by the presently available technology because of the oscillatory nature of beta cell metabolism. In fact it is more attractive to consider that variations in ADP rather than ATP regulate the $\mathrm{K}_{\text {ATP }}$ channel. Indeed, very small differences in the beta cell ATP content must be associated with large differences in ADP because the concentration of ATP is around $3000 \mu \mathrm{mol} / 1$ whereas free ADP is present at a concentration of $30 \mu \mathrm{mol} / \mathrm{l}$ in islet tissue [60]. ATP and ADP have antagonistic actions on the $\mathrm{K}_{\text {ATP }}$ channel [62]. Furthermore there is evidence for the existence of two sites of regulation of the $\mathrm{K}_{\mathrm{ATP}}$ channel by adenine nucleotides [63]. The first site binds ATP and the second binds Mg ADP acting as an antagonist since the channel opening probability decreases when ADP decreases [63] (Fig.2). Thus, ADP rather than ATP now emerges as a putative 


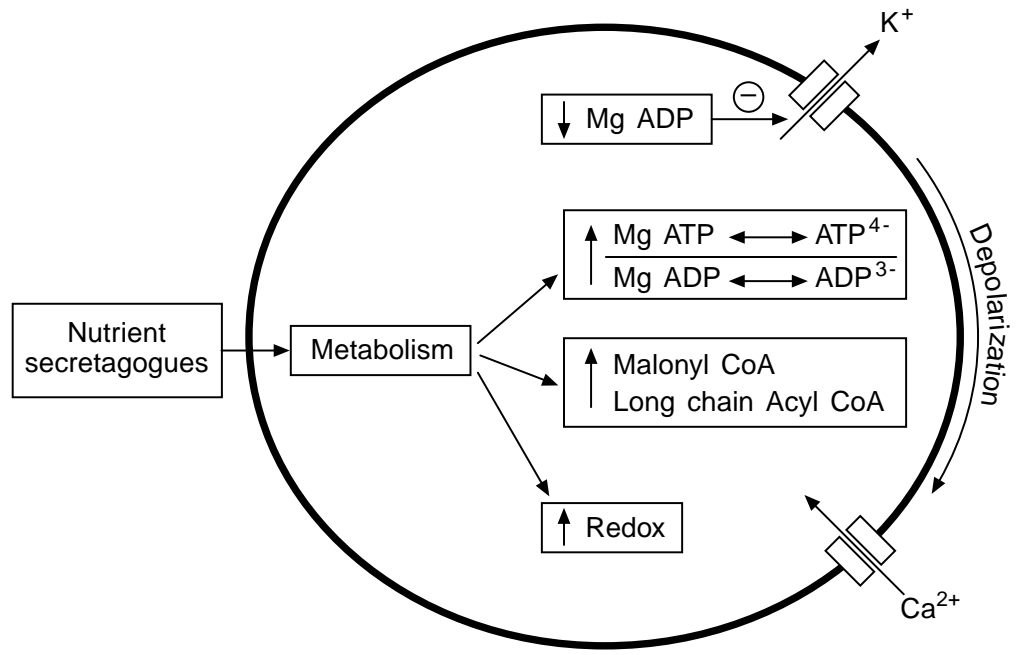

Fig. 2. The metabolism of nutrient secretagogues generate coupling factors. The figure also illustrates the concept that variations of ADP rather than ATP regulate the metabolically sensitive $\mathrm{K}^{+}$channel coupling factor as far as adenine nucleotides are concerned. Consistent with this view, it has been reported that a mutation of the sulphonylurea receptor (SUR), in an individual diagnosed with persistent hyperinsulinaemic hypoglycaemia, generated $\mathrm{K}_{\mathrm{ATP}}$ channels with normal ATP sensitivity, but altered antagonistic action of ADP [64].

The possibility that reducing equivalents, in particular NAD $(\mathrm{P}) \mathrm{H}$, directly modulate the signal transducing machinery of the beta cell has long been considered. A close relationship exists between the glucose concentration, the NADH/NAD ${ }^{+}$and $\mathrm{NADPH} / \mathrm{NADP}^{+}$ratios and insulin release [2]. However, one study showed that glucose has no effect on the cytosolic $\mathrm{NADH} / \mathrm{NAD}^{+}$ratio [65] whereas another reported that cytosolic NADH increases only after the initiation of insulin secretion [66]. Various combinations of fuel stimuli either increased or decreased the cytosolic NADPH/NADP ${ }^{+}$ratio [65]. One of the earliest events in beta-cell activation which precedes the rise in $\mathrm{Ca}^{2+}$ and secretion is an increase in $\mathrm{NAD}(\mathrm{P}) \mathrm{H}[21]$. This demonstrates that the initial changes in metabolism are not the consequence of the rise in $\mathrm{Ca}^{2+}$ or secretion. Nonetheless at present there is no convincing evidence demonstrating that the rise in the beta-cell redox state plays an important role other than that related to the generation of ATP as in all tissues.

M alonyl-CoA and long-chain acyl-CoA esters: two new candidate metabolic coupling factors

The islets of Langerhans contain substantial amounts of triglycerides and the endogenous fat store is the principal source of energy of the beta cell at low glucose [67]. An early metabolic event caused by glucose in the islet is a shift from fatty acid to glucose as an oxidative fuel [68]. In other tissues this occurs through conversion of glucose to malonyl-CoA, which, by inhibiting carnitine palmitoyl-transferase I (CPT I) blocks the rate-limiting step of mitochondrial fatty acid oxidation [69]. We have proposed that the generation of malonyl CoA is a central event in beta cell activation by fuels $[4,50,70,71]$. This hypothesis is attractive from a teleological standpoint because it implies that the same 'signal of plenty' (i.e. malonylCoA) tells the target tissues of insulin to synthesise, spare and store fat, and the beta cell to secrete the anabolic hormone insulin which favours lipogenesis and lipid esterification. The present evidence in support of this emerging concept, which remains to be

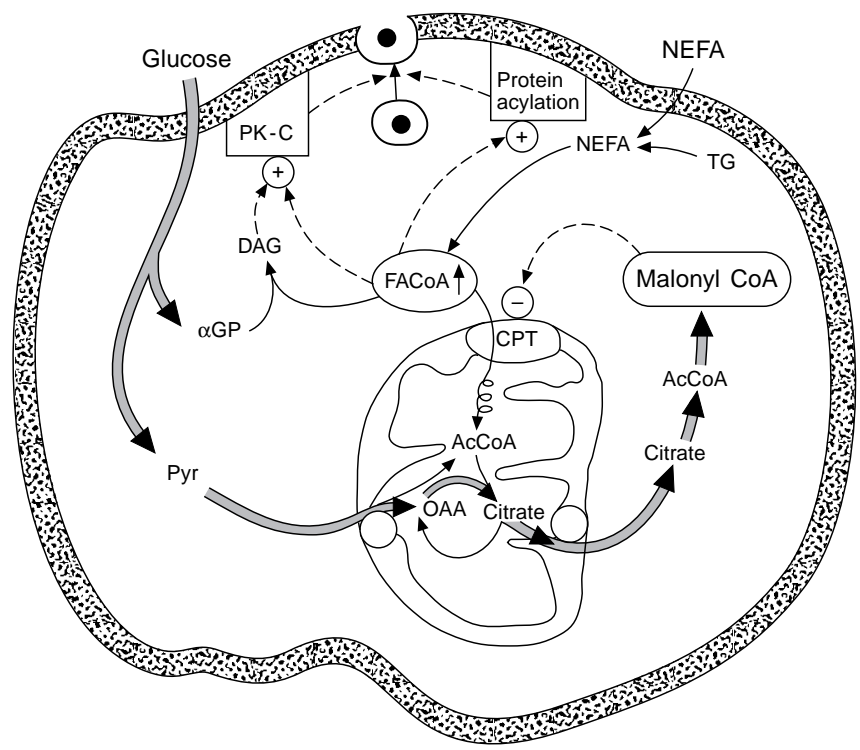

Fig. 3. Model illustrating the possible role of malonyl-CoA and long chain acyl-CoA esters in glucose-induced insulin release. Pyr, Pyruvate; $\alpha$-GP, glycerol 3-phosphate; AcCoA, acetyl-CoA; OAA, oxaloacetate; CPT, carnitine palmitoyltransferase I; ACC, acetyl-CoA carboxylase; TG, triacylglycerol; NEFA, non-esterified fatty acid; FACoA, long chain acyl-CoA ester; DAG, diacylglycerol; PK-C, protein kinase C 
formally proven, is summarised below (see also Figs. 1 and 3 ).

1) Glucose causes a large increase in beta (HIT) cell and islet malonyl-CoA which precedes secretion and is sustained for more than $30 \mathrm{~min}$ [50]. Only those nutrients and combinations of nutrients which elevate malonyl-CoA are secretagogues [56]. 2) Similarly, glucose rapidly elevates citrate, the carbon precursor of malonyl-CoA and only nutrients or combined nutrients which elevate citrate are efficient secretagogues [55]. 3) Some authors [50, 72], but not all [73], reported that glucose causes a rise in the Ckinase activator diacylglycerol. This is consistent with the view that esterification processes are promoted by glucose due to the availability of glucosederived glycerol 3-phosphate and of fatty acyl-CoA due to CPT I inhibition (Fig.3). 4) Exogenous long chain fatty acids acutely cause a rise in the beta-cell content of LC-CoA and potentiate glucose-induced insulin secretion [56]. 5) The CPT I inhibitors 2bromopalmitate and etomoxir induce secretion at low glucose levels [56, 74]. 6) 2-bromopalmitate restores sensitivity to islets from fasted animals [75, 76], fetal islets and islets from very young rats [77]. 7) Inhibition of the pathway of malonyl-CoA formation with hydroxy-citrate, which impairs citrate lyase activity, curtails glucose-induced secretion [74]. 8) Basal secretion in cells preincubated for $48 \mathrm{~h}$ at various glucose concentrations correlates with the beta (INS) cell content of acetyl-CoA carboxylase (ACC), the enzyme which forms malonyl-CoA [78]. 9) Fatty acid synthase, the enzyme which uses malonyl-CoA for palmitate synthesis, is present at an extremely low level in islet tissue [55]. This should favour the rapid accumulation of malonyl-CoA and indicates that the principal function of malonyl-CoA in the beta cell is not to serve as substrate for lipid biogenesis but is rather to inhibit CPT I and fatty acid oxidation.

It must be underlined that there is not a close correlation between the beta-cell content of malonylCoA and secretion stimulated by various fuel stimuli but rather between LC-CoA and insulin release [56]. This observation and the fact that CPT I inhibitors which bypass the formation of malonyl-CoA induce secretion $[56,74]$ gives support to the idea that LCCoA rather than malonyl-CoA acts as a 'coupling factor effector'. This however does not dismiss the importance of malonyl-CoA which acts as a 'coupling factor regulator'. Thus, by inhibiting CPT I it allows the accumulation of LC-CoA in the cytoplasm (Fig.3). It remains to be shown that LC-CoA increases specifically in the cytoplasmic compartment upon glucose stimulation. This is not an easy task due to the lipid and protein binding properties of the LC-CoA molecule and that the vast majority of LC$\mathrm{CoA}$ is bound to high affinity fatty acyl CoA binding proteins [79].
There are several ways by which malonyl-CoA may influence beta-cell metabolism and insulin secretion. First, it may play an important role in the metabolism of glucose by redirecting islet metabolism from fatty acid oxidation at low glucose levels to glucose utilisation at elevated concentrations of the sugar. Second, and as discussed above, by inhibiting CPT I it allows the cytosolic accumulation of LC-CoA acting themselves directly as effectors or indirectly via the formation of complex lipids such as lyso-phosphatidic acid, phosphatidic acid and diacylglycerol. With respect to a direct action of LCCoA, three possibilities must be mentioned. LCCoA may alter the activity of C-kinase enzymes [80] or change the palmitoylation state of signal transducing proteins such as trimeric $\mathrm{G}$ proteins implicated in exocytosis [81]. LC-CoA may also induce the fusion of secretory granules with the plasma membrane. This suggestion is derived by analogy to the observation that LC-CoA accelerate the traffic of vesicles between Golgi elements, in particular by promoting the fusion of cis-Golgi-derived vesicles to the trans-Golgi compartment [82]. Third, by changing the concentration of LC-CoA, malonylCoA may have pronounced effects on the expression level of genes encoding metabolic enzymes involved in the fuel sensing process (see below) and other beta-cell processes. Thus, there is little doubt that malonyl-CoA will prove to be of central importance in the regulation of several islet functions. The challenge now is the formal identification of these processes using a combination of experimental approaches, i.e. biochemical and biophysical methods, pharmacological agents and the tools of molecular biology.

\section{G lucose and fatty acid regulation of genes encoding metabolic enzymes}

In addition to their actions on insulin release and biosynthesis, nutrients have pronounced effects on the expression level of genes encoding metabolic enzymes. This new aspect of beta-cell research has implications for our understanding of the pathogenesis of obesity and NIDDM. Using pancreatic islets or INS cells it has been shown that glucose induces the transporter GLUT2 [83], the PFK-1 isozymes (C, M and L) [84], glyceraldehyde 3-phosphate dehydrogenase [84] and the L-PK [84, 85] genes in the glycolytic pathway. Glucose also increases the level of expression of the anaplerotic enzyme PC [86] and ACC [78] in the pathway of malonyl-CoA formation. Interestingly, glucose decreases the expression of the branched-chain $\alpha$-keto-acid dehydrogenase transcript in cultured islets [87]. These findings suggest that glucose, when abundant, favours the expression of enzymes implicated in its metabolism and represses 


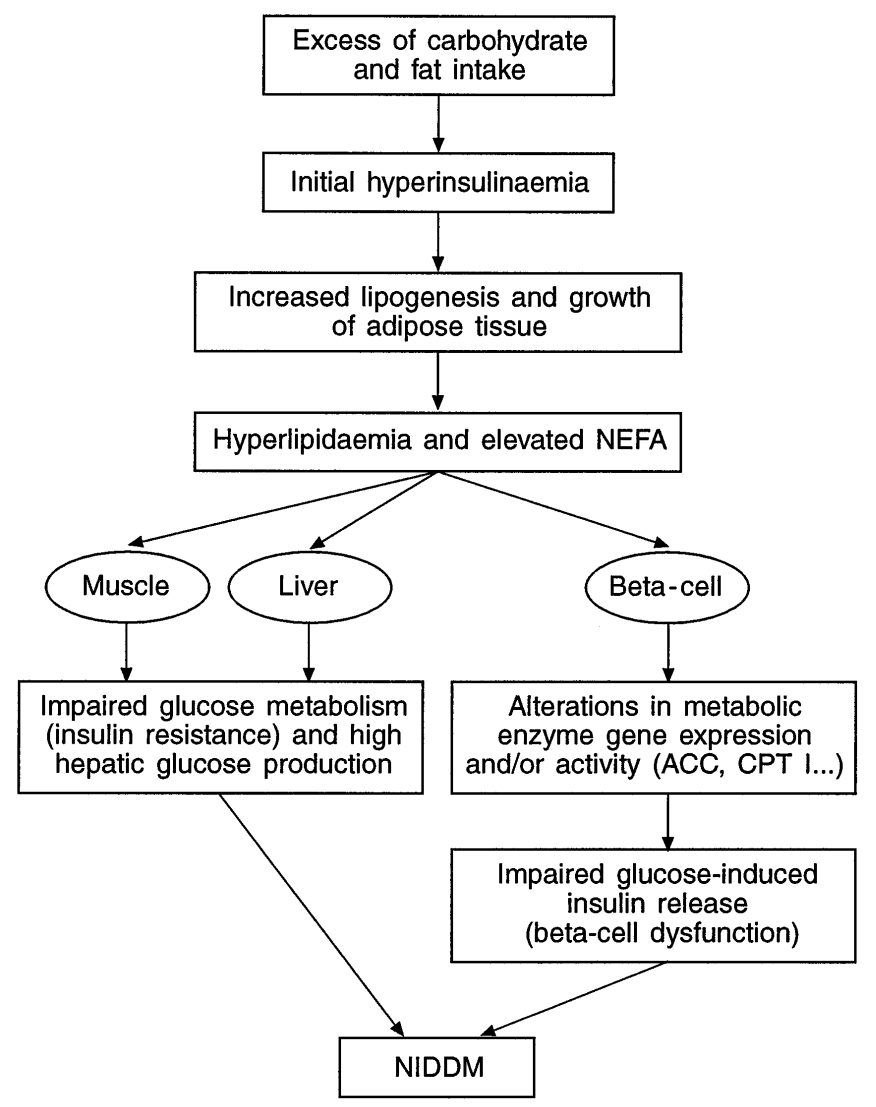

Fig. 4. A nutritional model for the pathogenesis of NIDDM. Excessive intake of both carbohydrate and fat affects the target tissues of insulin and the beta cell by changing the expression level of genes encoding metabolic enzymes, in particular acetyl-CoA carboxylase and carnitine palmitoyl-transferase I

others that specifically metabolise other fuel stimuli such as leucine.

In contrast to all expectations, the mechanism by which glucose regulates genes coding for metabolic enzymes is entirely different from that by which it causes secretion. Glucose induction of ACC mRNA is highly specific since, except for mannose, other fuels do not induce the gene [78]. Furthermore, it does not require metabolism of the hexose beyond the glucokinase step and is not mediated by the $\mathrm{Ca}^{2+}$, cAMP and C-kinase transduction systems [78]. The action of glucose on this class of genes is apparently transcriptional. A carbohydrate response element has been identified in the promoter of the rat liver S14 and LPK [88] genes. It most likely mediates induction in the beta cell as well [85]. Thus, glucose causes a co-ordinated induction of gene encoding metabolic enzymes in the glycolytic pathway as well as in the pathway of malonyl-CoA formation from pyruvate in the $\beta$ (INS) cell [84].

Long chain fatty acids (NEFA) also change the expression of key metabolic enzymes. Using INS cells we have observed that various NEFA counteract the action of glucose on the ACC gene [89] and markedly induce the liver type CPT I gene at the transcriptional level [90]. These late actions of fatty acids correlated with elevated fatty acid oxidation and altered insulin secretion [89, 90]. Hence, glucose and fatty acids have pronounced long-term effects on the expression levels of several genes in the glycolytic and anaplerotic/malonyl-CoA pathways. Much remains to be learned about the mechanism by which they exert these effects and the biological implications of this phenomenon.

\section{N utritional and clinical implications}

Obesity and NIDDM are heterogeneous diseases from a genetic point of view. Mutations in the glucokinase gene [91] and a number of other genes have been observed in some forms of NIDDM. However, all the mutations which have been found so far account for a very small number of all the cases of NIDDM [92]. Thus, many additional genes involved in obesity and NIDDM remain to be identified. If the anaplerotic/malonyl-CoA pathway is implicated in the regulation of insulin secretion or beta-cell proliferation, it becomes very attractive to hypothesize that mutations in genes coding for enzymes in this pathway may cause diabetes. In this respect, ACC is a prime candidate because it is a highly regulated enzyme which catalyses malonyl-CoA formation and the rate-limiting step in fatty acid biogenesis. Another excellent candidate is an isoform of CPT I because it catalyses the rate-limiting step of fatty acid oxidation. Thus, fuel partitioning, which is the balance of fatty acid oxidation, synthesis, esterification and glucose utilisation, is primarily controlled by metabolic fluxes through ACC and CPT I [69]. Alterations in the activity of these two enzymes should affect glucose and lipid metabolism in the beta cell and in the target tissues of insulin as well [71].

The environmental and nutritional factors implicated in the pathogenesis of NIDDM are also poorly defined. On the basis of what we have discussed above, we would like to propose that exaggerated intake of both lipids and carbohydrates may, in genetically susceptible individuals, cause obesity and NIDDM via the altered expression level of metabolic enzymes, in particular ACC and CPT I (Fig. 4). Elevated NEFA are known to cause muscle insulin resistance and favour exaggerated production of glucose by the liver [93]. With respect to the beta cell, exaggerated fat intake in rat [94] and long-term exposure of islets to elevated NEFA in vivo [95] or in vitro $[90,96,97]$, impair glucose-induced insulin secretion. Interestingly, various NEFA induce CPT I mRNA and repress the ACC gene in $\beta$ (INS) cells (see above). In this aetiology of the disease, brief episodes of elevated glucose and fatty acids would initially favour hyperinsulinaemia which may precipitate 
insulin resistance by promoting hyperlipidaemia [93]. It must be mentioned for the sake of clarity that short-term exposure of beta cells to NEFA potentiates glucose-induced insulin secretion [56] whereas long-term exposure of islets to NEFA impairs glucose-induced insulin release [97]. Clearly, at this stage, our proposal remains a hypothesis; but it is experimentally testable and is entirely compatible with the data in the presently available literature.

$\mathrm{N}$ ote added in proof: NADH fluorescence oscillations indicative of glycolytic oscillations have been demonstrated in islet extracts (Civelek VN, Deenzy JT, Fusonie GE, Corkey BE, Tornheim K (1997) Oscillations in oxygen consumption by permeabilized clonal pancreatic beta cells (HIT) incubated in an oscillatory glycolyzing muscle extract. Roles of free $\mathrm{Ca}^{2+}$, substrates and the ATP/ADP ratio. Diabetes 46: 51-56

A cknowledgements. The work of our laboratories is supported grants from the Medical Research Council of Canada and the Canadian Diabetes Association to M.P., by NIH grants DK 35914 and DK 46200 and Juvenile Diabetes Foundation grant 195014 to B.E.C. and by NIH grant DK 53064 IDF grant 196123 and a grant from the Am. Diabetes Assoc. to K. T.

\section{References}

1. Hedeskov CJ (1980) Mechanism of glucose-induced insulin secretion. Physiol Rev 60: 442-509

2. Malaisse WJ, Sener A, Herchuelz A, Hutton JC (1979) Insulin release: the fuel hypothesis. Metabolism 28: 373-386

3. Matschinsky FM (1996) A lesson in metabolic regulation inspired by the glucokinase glucose sensor paradigm. Diabetes 45: 223-241

4. Prentki M (1996) New insights into pancreatic beta-cell metabolic signaling in insulin secretion. Eur J Endocrinol 134: $272-286$

5. Newgard CB, McGarry JD (1995) Metabolic coupling factors in pancreatic beta-cell signal transduction. Annu Rev Biochem 64: 689-719

6. Thorens B (1995) Glucagon-like peptide-1 and control of insulin secretion. Diabete Metab 21: 311-318

7. Ashcroft FM, Rorsman P (1990) ATP-sensitive $\mathrm{K}^{+}$channels: a link between beta-cell metabolism and insulin secretion. Biochem Soc Trans 18: 109-111

8. Aizawa T, Sato Y, Ishihara F et al. (1994) ATP-sensitive $\mathrm{K}^{+}$ channel-independent glucose action in rat pancreatic $\beta$ cell. Am J Physiol 266:C622-C627

9. Gembal M, Gilon P, Henquin JC (1992) Evidence that glucose can control insulin release independently from its action on ATP-sensitive $\mathrm{K}^{+}$channels in mouse beta cells. $\mathrm{J}$ Clin Invest 89: 1288-1295

10. Lefèbvre PJ, Paolisso G, Scheen AJ, Henquin JC (1987) Pulsatility of insulin and glucagon release: physiological significance and pharmacological implications. Diabetologia 30: 443-452

11. Weigle DS (1987) Pulsatile secretion of fuel-regulatory hormones. Diabetes 36: 764-775

12. O'Rahilly S, Turner RC, Matthews DR (1988) Impaired pulsatile secretion of insulin in relatives of patients with non-insulin-dependent diabetes N. Engl. J. Med. 318: 1225-1230

13. Longo EA, Tornheim K, Deeney JT et al. (1991) Oscillations in cytosolic free $\mathrm{Ca}^{2+}$, oxygen consumption, and insulin secretion in glucose-stimulated rat pancreatic islets. $\mathbf{J}$ Biol Chem 266: 9314-9319
14. Cunningham BA, Deeney JT, Bliss CR, Corkey BE, Tornheim K (1996) Glucose-induced oscillatory insulin secretion in perifused rat pancreatic islets and clonal beta-cells (HIT). Am J Physiol 34:E702-E710

15. Bergstrom RW, Fujimoto WY, Teller DC, de Haën C (1989) Oscillatory insulin secretion in perifused isolated rat islets. Am J Physiol 257:E479-E485

16. Chou H-F, Ipp E (1990) Pulsatile insulin secretion in isolated rat islets. Diabetes 39: 112-117

17. Shapiro ET, Strasser S, Polonsky KS, Alejandro R, Mintz DM (1991) Persistence of oscillatory insulin secretion in denervated islet cell autografts. Transplantation 52: 574 576

18. Chou H-F, Berman N, Ipp E (1992) Oscillations of the lactate released from the islets of Langerhans: evidence for oscillatory glycolysis in beta-cells. Am J Physiol 262:E800-E805

19. Gilon P, Shepherd RM, Henquin JC (1993) Oscillations of secretion driven by oscillations of cytoplasmic $\mathrm{Ca}^{2+}$ as evidence in single pancreatic islets. J Biol Chem 268: 2226522268

20. Valdeolmillos M, Nadal A, Soria B, Garcia-Sancho J (1993) Fluorescence digital image analysis of glucose-induced $\left[\mathrm{Ca}^{2+}\right]_{i}$ oscillations in mouse pancreatic islets of Langerhans. Diabetes 42: 1210-1214

21. Pralong WF, Bartley C, Wollheim CB (1990) Single islet beta-cell stimulation by nutrients: relationship between pyridine nucleotides, cytosolic $\mathrm{Ca}^{2+}$ and secretion. EMBO J 9: 53-60

22. Pralong W-F, Spät A, Wollheim CB (1994) Dynamic pacing of cell metabolism by intracellular $\mathrm{Ca}^{2+}$ transients. $\mathrm{J}$ Biol Chem 269: 1-5

23. Valdeolmillos M, Santos RM, Contreras D, Soria B, Rosario LM (1989) Glucose-induced oscillations of intracellular $\mathrm{Ca}^{2+}$ concentration resembling bursting electrical activity in single mouse islets of Langerhans. FEBS Lett 259: 19-23

24. Tornheim K, Lowenstein JM (1974) The purine nucleotide cycle IV. Interaction with oscillations of the glycolytic pathway in muscle extracts. J Biol Chem 249: 3241-3247

25. Tornheim K, Andrés V, Schultz V (1991) Modulation by citrate of glycolytic oscillations in skeletal muscle extracts. J Biol Chem 266: 15675-15678

26. Chance B, Schoener B, Elsaesser S (1965) Metabolic control phenomena involved in damped sinusoidal oscillations of reduced diphosphopyridine nucleotide in a cell-free extract of saccharomyces carlsbergensis. J Biol Chem 240: 3170-3181

27. Hess B, Boiteux A (1971) Oscillatory phenomena in biochemistry. Annu Rev Biochem 40: 237-258

28. Frenkel R (1968) Control of reduced diphosphopyridine nucleotide oscillations in beef heart extracts. II. Oscillations of glycolytic intermediates and adenine nucleotides. Arch Biochem Biophys 125: 157-165

29. Ibsen KH, Schiller KW (1967) Oscillations of nucleotides and glycolytic intermediates in aerobic suspensions of Erlich ascites tumor cells. Biochim Biophys Acta 131: 405-407

30. Tornheim K (1988) Fructose 2,6-bisphosphate and glycolytic oscillations in skeletal muscle extracts. J Biol Chem 263: 2619-2624

31. Andrés V, Schultz V, Tornheim K (1990) Oscillatory synthesis of glucose 1,6-bisphosphate and frequency modulation of glycolytic oscillations in skeletal muscle extracts. J Biol Chem 265: 21441-21447

32. Corkey BE, Tornheim K, Deeney JT et al. (1988) Linked oscillations of free $\mathrm{Ca}^{2+}$ and the ATP/ADP ratio in permeabilized RINm5F insulinoma cells supplemented with a glycolyzing cell-free muscle extract. J Biol Chem 263: 42544258 
33. Gilon P, Henquin JC (1992) Influence of membrane potential changes on cytoplasmic $\mathrm{Ca}^{2+}$ concentration in an electrically excitable cell, the insulin-secreting pancreatic Bcell. J Biol Chem 267: 20713-20720

34. Nilsson T, Schultz V, Berggren PO, Corkey BE, Tornheim $\mathrm{K}$ (1996) Temporal patterns of changes in ATP/ADP ratio, glucose 6-phosphate and cytoplasmic free $\mathrm{Ca}^{2+}$ in glucosestimulated pancreatic beta-cells. Biochem J 314: 91-94

35. Berridge MJ, Rapp PE (1979) A comparative survey of the function, mechanism and control of cellular oscillators. J Exp Biol 81: 217-279

36. Berridge MJ (1990) Calcium oscillations. J Biol Chem 265: 9583-9586

37. Dunaway GA, Kasten TP (1987) Nature of the subunits of the 6-phosphofructo-1-kinase isoenzymes from rat tissues. Biochem J 242: 667-671

38. Dunaway GA, Kasten TP, Sebo T, Trapp R (1988) Analysis of phosphofructokinase subunits and isoenzymes in human tissues. Biochem J 251: 677-683

39. Foe LG, Kemp RG (1985) Isolation and characterization of phosphofructokinase C from rabbit brain. J Biol Chem 260: 726-730

40. Kasten TP, Mhaskar Y, Dunaway GA (1993) Regulation of brain 6-phosphofructo-1-kinase: effect of aging, fructose2,6-bisphosphate, and regional subunit distribution. Mol Cell Biochem 120: 61-68

41. Tornheim K, Lowenstein JM (1976) Control of phosphofructokinase from rat skeletal muscle: effect of fructose diphosphate, AMP, ATP and citrate. J Biol Chem 251: 7322-7328

42. Tornheim K (1985) Activation of muscle phosphofructokinase by fructose 2,6-bisphosphate and fructose 1,6-bisphosphate is differently affected by other regulatory metabolites. J Biol Chem 260: 7985-7989

43. Van Schaftingen E, Jett M-F, Hue L, Hers H-G (1981) Control of liver 6-phosphofructokinase by fructose 2,6-bisphosphate and other effectors. Proc Natl Acad Sci USA 78: 3483-3486

44. Malaisse WJ, Sener A, Levy J (1976) The stimulus-secretion coupling of glucose-induced insulin release. Fasting-induced adaptation of key glycolytic enzymes in isolated islets. J Biol Chem 251: 1731-1737

45. Malaisse WJ, Malaisse-Lagae F, Sener A, van Schaftingen E, Hers HG (1981) Is the glucose-induced stimulation of glycolysis in pancreatic islets attributable to activation of phosphofructokinase by fructose 2,6-bisphosphate? FEBS Lett 125: 217-219

46. Matschinsky FM, Rutherford CR, Ellerman JE (1968) Accumulation of citrate in pancreatic islets of obese hyperglycemic mice. Biochem Biophys Res Commun 33: 855-862

47. Yaney GC, Schultz V, Cunningham BA, Dunaway GA, Corkey BE, Tornheim K (1995) Phosphofructokinase isozymes in pancreatic islets and clonal beta-cells (INS-1). Diabetes 44: 1285-1289

48. Meglasson MD, Matschinsky FM (1986) Pancreatic islet glucose metabolism and regulation of insulin secretion. Diabetes Metab Rev 2: 163-214

49. Malaisse WJ, Sener A, Malaisse-Lagae F et al. (1982) The stimulus-secretion coupling of amino acid-induced insulin release. Metabolic response of pancreatic islets of L-glutamine and L-leucine. J Biol Chem 257: 8731-8737

50. Corkey BE, Glennon MC, Chen KS, Deeney JT, Matschinsky FM, Prentki M (1989) A role for malonyl-CoA in glucose-stimulated insulin secretion from clonal pancreatic beta-cells. J Biol Chem 264: 21608-21612

51. Prentki M, Visher S, Brun T, Glennon MC, Corkey BE (1991) Metabolic coupling factors in $\beta$-cell insulin secretion.
In: Rifkin H, Colwell JA, Taylor SI (eds) Diabetes 1991. Elsevier Science Publishers pp 156-160

52. MacDonald MJ (1995) Feasibility of a mitochondrial pyruvate malate shuttle in pancreatic islets. Further implication of cytosolic NADPH in insulin secretion. J Biol Chem 270: 20051-20058

53. MacDonald MJ (1990) Elusive proximal signals of $\beta$-cells for insulin secretion. Diabetes 39: 1461-1466

54. Sener A, Malaisse WJ (1991) Hexose metabolism in pancreatic islets. Effect of (-)-hydroxycitrate upon fatty acid synthesis and insulin release in glucose-stimulated islets. Biochimie 73: 1287-1290

55. Brun T, Roche E, Assimacopoulos-Jeannet F, Corkey BE, Kim KH, Prentki M (1996) Evidence for an anaplerotic malonyl-CoA pathway in pancreatic beta-cell nutrient signaling. Diabetes 45: 190-198

56. Prentki M, Vischer S, Glennon MC, Regazzi R, Deeney JT, Corkey BE (1992) Malonyl-CoA and long chain acyl-CoA esters as metabolic coupling factors in nutrient-induced insulin secretion. J Biol Chem 267: 5802-5810

57. Hutton JC, Sener A, Herchuelz A et al. (1980) Similarities in the stimulus-secretion coupling mechanisms of glucoseand 2-keto acid-induced insulin release. Endocrinology 106: 203-219

58. Eddlestone GT (1995) ATP-sensitive K channel modulation by products of $\mathrm{PLA}_{2}$ action in the insulin-secreting HIT cell. Am J Physiol 268:C181-C190

59. Dunne MJ, Findlay I, Petersen OH (1988) Effects of pyridine nucleotides on the gating of ATP-sensitive potassium channels in insulin-secreting cells. J Membr Biol 102: 205216

60. Ghosh A, Ronner P, Cheong E, Khalid P, Matschinsky FM (1991) The role of ATP and free ADP in metabolic coupling during fuel-stimulated insulin release from islet betacells in the isolated perfused rat pancreas. J Biol Chem 266: 22887-22892

61. Meglasson MD, Nelson J, Nelson D, Erecinska M (1989) Bioenergetic response of pancreatic islets to stimulation by fuel molecules. Metabolism 38: 1188-1195

62. Kakei M, Kelly RP, Ashcroft SJH, Ashcroft FM (1986) ATP-sensitivity of $\mathrm{K}^{+}$channels in rat pancreatic beta-cells is modulated by ADP. FEBS Letters 208: 63-66

63. Hopkins WF, Fatherazi S, Peter-Riesch B, Corkey BE, Cook DL (1992) Two sites for adenine-nucleotide regulation of ATP-sensitive potassium channels in mouse pancreatic $\beta$-cells and HIT cells. J Membr Biol 129: 287-295

64. Nichols CG, Shyng SL, Nestorowicz A et al. (1996) Adenosine diphosphate as an intracellular regulator of insulin secretion. Science 272: 1785-1787

65. Hedeskov CJ, Capito K, Thams P (1987) Cytosolic ratios of free $[\mathrm{NADPH}] /\left[\mathrm{NADP}^{+}\right]$and $[\mathrm{NADH}] /\left[\mathrm{NAD}^{+}\right]$in mouse pancreatic islets, and nutrient-induced insulin secretion. Biochem J 241: 161-167

66. Matschinsky FM, Ghosh AK, Meglasson MD, Prentki M, June V, von Allman D (1986) Metabolic concomitants in pure, pancreatic beta cells during glucose-stimulated insulin secretion. J Biol Chem 261: 14057-14061

67. Malaisse WJ, Best L, Kawazu S, Malaisse-Lagae F, Sener A (1983) The stimulus-secretion coupling of glucoseinduced insulin release: fuel metabolism in islets deprived of exogenous nutrient. Arch Biochem Biophys 224: 102110

68. Sener A, Malaisse WJ (1984) Nutrient metabolism in islet cells. Experientia 40: 1026-1035

69. McGarry JD, Woeltje KF, Kuwajima M, Foster DW (1989) Regulation of ketogenesis and the renaissance of carnitine palmitoyltransferase. Diabetes Metab Rev 5: 271-284 
70. Prentki M, Matschinsky FM (1987) $\mathrm{Ca}^{2+}$, cAMP, and phospholipid-derived messengers in coupling mechanisms of insulin secretion. Physiol Rev 67: 1185-1248

71. Prentki M, Corkey BE (1996) Are the beta-cell signaling molecules malonyl-CoA and cystolic long-chain acyl-CoA implicated in multiple tissue defects of obesity and NIDDM? Diabetes 45: 273-283

72. Peter-Riesch B, Fathi M, Schlegel W, Wollheim CB (1988) Glucose and carbachol generate 1,2-diacylglycerols by different mechanisms in pancreatic islets. J Clin Invest 81: 1154-1161

73. Wolf BA, Easom RA, McDaniel ML, Turk J (1990) Diacylglycerol synthesis de novo from glucose by pancreatic islets isolated from rats and humans. J Clin Invest 85: 482-490

74. Chen S, Ogawa A, Ohneda M, Unger RH, Foster DW, McGarry JD (1994) More direct evidence for a malonylCoA-carnitine palmitoyltransferase I interaction as a key event in pancreatic beta-cell signaling. Diabetes 43: 878883

75. Bedoya FJ, Ramirez R, Arilla E, Goberna R (1984) Effect of 2-bromostereate on glucose-phosphorylation activities and the dynamics of insulin secretion in islets of Langerhans during fasting. Diabetes 33: 858-863

76. Vara E, Tamarit-Rodriguez J (1986) Glucose stimulation of insulin secretion in islets of fed and starved rats and its dependence on lipid metabolism. Metabolism 35: 266-271

77. Bliss CR, Sharp GW (1992) Glucose-induced insulin release in islets of young rats: time-dependent potentiation and effects of 2-bromostearate. Am J Physiol 263:E890 E896

78. Brun T, Roche E, Kim KH, Prentki M (1993) Glucose regulates acetyl-CoA carboxylase gene expression in a pancreatic beta-cell line (INS-1). J Biol Chem 268: 18905-18911

79. Waku K (1992) Origins and fates of fatty acyl-CoA esters. Biochim Biophys Acta 1124: 101-111

80. Bronfman M, Morales MN, Orellana A (1988) Diacylglycerol activation of protein kinase $\mathrm{C}$ is modulated by long chain acyl-CoA. Biochem Biophys Res Commun 152: 987992

81. Casey PJ (1995) Protein lipidation and cell signaling. Science 268: 221-225

82. Pfanner N, Orci L, Glick BS, Amherdt M, Arden SR, Malhotra V, Rothman JE (1989) Fatty acyl-coenzyme A is required for budding of transport vesicles from Golgi cisternae. Cell 59: 95-102

83. Waeber G, Thomson N, Haefliger J-A, Nicod P (1994) Characterization of the murine high $\mathrm{K}_{\mathrm{m}}$ glucose transporter GLUT2 gene and its transcriptional regulation by glucose in a differentiated insulin secreting cell line. J Biol Chem 269: 26912-26919

84. Roche E, Assimacopoulos-Jeannet F, Witters LA, Perruchoud B, Yaney GC, Corkey BE, Asfari M, Prentki M (1997) Induction by glucose of genes coding for glycolytic enzymes in a pancreatic beta-cell line (INS-1). J Biol Chem 272: 3091-3098

85. Marie S, Diaz-Guerra MJ, Miquerol L, Kahn A, Iynedjian PB (1993) The pyruvate kinase gene as a model for studies of glucose-dependent regulation of gene expression in the endocrine pancreatic beta-cell type. J Biol Chem 268: 23881-23890

86. MacDonald MJ, Kaysen JH, Moran SM, Pomije CE (1991) Pyruvate dehydrogenase and pyruvate decarboxylase: sites of pretranslational regulation by glucose of glucose-induced insulin release in pancreatic islets. J Biol Chem 266: 22392-22397

87. MacDonald MJ, McKenzie DI, Kaysen JH et al. (1991) Glucose regulates leucine-induced insulin release and the expression of the branched chain ketoacid dehydrogenase E1 alpha subunit gene in pancreatic islets. J Biol Chem 266: $1335-1340$

88. Shih H-M, Towle HC (1994) Definition of the carbohydrate response element of the rat $\mathrm{S} 14$ gene. Context of the CACGTG motif determines the specificity of carbohydrate regulation. J Biol Chem 269: 9380-9387

89. Brun T, Assimacopoulos-Jeannet F, Corkey BE, Prentki M (1997) Long chain fatty acids inhibit acetyl-CoA carboxylase gene expression in the B cell line INS-1. Diabetes 46: 393-400

90. Assimacopoulos-Jeannet F, Thumelin S, Roche E, Esser V, McGarry JD, Prentki M (1997) Fatty acids rapidly induce the carnitine palmitoyltransferase I gene in the pancreatic $\beta$-cell line INS-1. J Biol Chem 272: 1659-1664

91. Froguel P, Zouali H, Vionnet N et al. (1993) Familial hyperglycemia due to mutations in glucokinase. Definition of a subtype of diabetes mellitus. New Engl J Med 328: 697-702

92. Kahn CR, Vicent D, Doria A (1996) Genetics of non-insulin-dependent (type-II) diabetes mellitus. Ann Rev Med 47: 509-531

93. Reaven GM (1988) Role of insulin resistance in human diabetes. Diabetes 37: 1595-1607

94. Capito K, Hansen SE, Hedeskov CJ, Islin H, Thams P (1992) Fat-induced changes in mouse pancreatic islet insulin secretion, insulin biosynthesis and glucose metabolism. Acta Diabetol 28: 193-198

95. Sako Y, Grill VE (1990) A 48-hour lipid infusion in the rat, time-dependently inhibits glucose-induced insulin secretion and $\beta$-cell oxidation through a process likely to be coupled to fatty acid oxidation. Endocrinology 127: 1580-1589

96. Lee Y, Hirose H, Makoto O, Johnson JH, McGarry JD, Unger RH (1994) Beta-cell lipotoxicity in the pathogenesis of non-insulin-dependent diabetes mellitus of obese rats: impairment in adipocyte-beta-cell relationships. Proc Natl Acad Sci USA 91: 10878-10882

97. Zhou YP, Grill V (1995) Long term exposure to fatty acids and ketones inhibits B-cell functions in human pancreatic islets of Langerhans. J Clin Endocrinol Metab 80: 15841590 